\title{
Radial artery versus saphenous vein as the second conduit for coronary artery bypass surgery: A meta-analysis
}

Mario Gaudino, MD, ${ }^{\mathrm{a}}$ Mohamed Rahouma, MD, ${ }^{\mathrm{a}}$ Ahmed Abouarab, MD, ${ }^{\mathrm{a}}$ Jeremy Leonard, MD, ${ }^{\mathrm{a}}$ Mohamed Kamel, MD, ${ }^{a}$ Antonino Di Franco, MD, ${ }^{a}$ Michelle Demetres, MLIS, ${ }^{b}$ Derrick Y. Tam, MD, Robert Tranbaugh, MD, ${ }^{a}$ Leonard N. Girardi, MD, ${ }^{a}$ and Stephen E. Fremes, MD

\section{ABSTRACT}

Objective: Individual studies may be limited by sample size to detect differences in late survival between radial artery (RA) or saphenous vein graft (SVG) as a second conduit for coronary artery bypass surgery. Here we undertook a meta-analysis of the best evidence available on the comparison of early and late clinical outcomes of the RA and the SVG.

Methods: MEDLINE and EMBASE were searched for studies comparing use of the RA versus SVG for isolated coronary artery bypass surgery. Time-to-event outcomes for long-term mortality, repeat revascularization, and myocardial infarction (MI) were extracted as incidence rate ratios (IRR) with $95 \%$ confidence intervals $(95 \% \mathrm{CI})$. Odds ratios (OR) were extracted for perioperative mortality, stroke, and MI. A random effects meta-analysis was performed. Sensitivity analyses included leave-one-out-analyses and meta-regression.

Results: Among 1201 articles, 14 studies (20,931 patients) were included (mean follow-up: 6.6 years). Operative mortality was $1.25 \%$ in the RA versus $1.33 \%$ in the SVG group (OR, 0.93; 95\% CI, 0.68-1.28). No difference in perioperative MI (OR, 0.96; 95\% CI, 0.59-1.56) or stroke (OR, 0.70; 95\% CI, 0.43-1.13) was found between RA and SVG. Long-term mortality (mean follow-up 6.6 years) was $24.5 \%$ in RA versus $34.2 \%$ in SVG group (IRR, 0.74; 95\% CI, 0.63-0.87, $P<.001)$. No difference in follow-up MI or repeat revascularization was found (IRR, 0.76; 95\% CI, 0.42-1.36 and IRR, 0.68; 95\% CI, 0.42-1.09 respectively). At meta-regression, RA survival advantage was independent of age, sex, diabetes, and ventricular function.

Conclusions: Compared with the SVG, using the RA as the second conduit is associated with a $26 \%$ relative risk reduction in mortality at 6.6-year follow-up. (J Thorac Cardiovasc Surg 2019;157:1819-25)

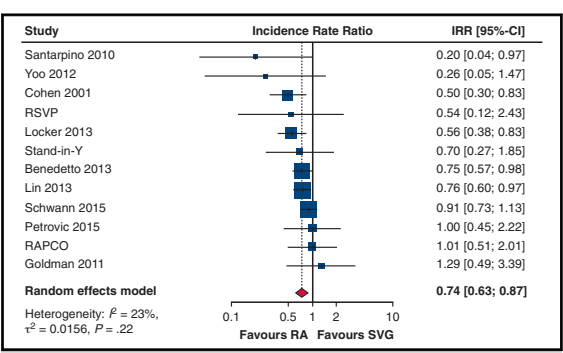

Forest plot for long-term mortality (expressed as incidence rate ratio)

Central Message

As compared with SVG, the use of the RA as the second conduit for CABG is associated with a $26 \%$ relative risk reduction in mortality at a mean follow-up of 6.6 years.

\section{Perspective}

This meta-analysis compares the radial artery (RA) versus the saphenous vein graft (SVG) for coronary artery bypass grafting (CABG) on clinically important outcomes. A total of 14 studies (20,931 patients) represents the best-available evidence on the comparison of the early and late clinical endpoints of the RA and the SVG for CABG.

See Commentary on page 1826.
Previous meta-analyses of the radial artery (RA) and saphenous vein graft (SVG) as a second conduit have focused on graft patency and have shown better mid-term patency rate for the RA. No previous aggregate

\footnotetext{
From the ${ }^{\mathrm{a}}$ Department of Cardiothoracic Surgery and ${ }^{\mathrm{b}}$ Samuel J. Wood Library \& C.V. Starr Biomedical Information Center, Weill Cornell Medicine, New York, NY; and ${ }^{\mathrm{c}}$ Schulich Heart Centre, Sunnybrook Health Sciences Centre, University of Toronto, Toronto, Ontario, Canada.

Read at the 98th Annual Meeting of The American Association for Thoracic Surgery, San Diego, California, April 28-May 1, 2018.

Received for publication March 4, 2018; revisions received Aug 24, 2018; accepted for publication Aug 30, 2018; available ahead of print Dec 11, 2018.

Address for reprints: Mario Gaudino, MD, Department of Cardiothoracic Surgery, Weill Cornell Medicine, 525 E 68th St, New York, NY 10065 (E-mail: mfg9004@med.cornell.edu).

$0022-5223 / \$ 36.00$

Copyright (c) 2018 by The American Association for Thoracic Surgery https://doi.org/10.1016/j.jtcvs.2018.08.123
}

meta-analysis has focused on the comparison of clinical outcomes after coronary artery bypass surgery (CABG). Evidence comparing the clinical results of the RA and SVG exist only from single-center observational studies. The outcomes of those studies may be heavily influenced by the individual surgeon's expertise with the RA and potential baseline differences in the patients selected for RA grafting such that a broader and more generalizable

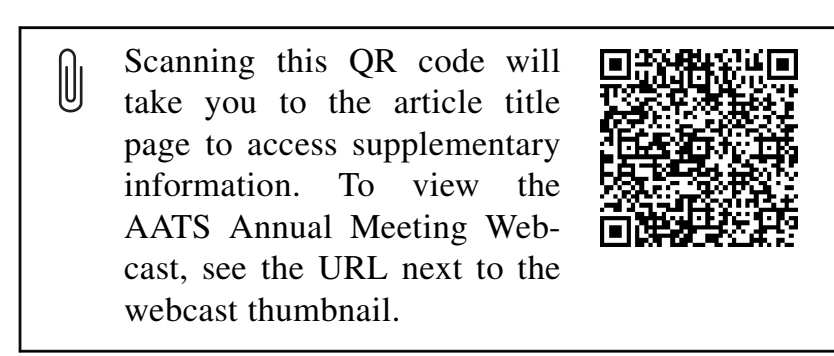




$$
\begin{aligned}
& \text { Abbreviations and Acronyms } \\
& \begin{aligned}
\text { CABG } & =\text { coronary artery bypass surgery } \\
\text { CI } & =\text { confidence interval } \\
\text { HR } & =\text { hazard ratio } \\
\text { IRR } & =\text { incidence rate ratio } \\
\text { MI } & =\text { myocardial infarction } \\
\text { OR } & =\text { odds ratio } \\
\text { RA } & =\text { radial artery } \\
\text { RCT } & =\text { randomized clinical trial } \\
\text { SVG } & =\text { saphenous vein graft }
\end{aligned}
\end{aligned}
$$

estimate of the clinical effect of the use of the RA for CABG at the moment is unclear.

The present meta-analysis is aimed at overcoming these limitations by aggregating data from both randomized clinical trials (RCTs) and adjusted observational studies to determine the best evidence regarding the comparison of the early and late clinical outcomes of the RA and the SVG used for CABG.

\section{METHODS}

This systematic review and meta-analysis follows the Preferred Reporting Items for Systematic Reviews and Meta-Analysis statement. ${ }^{2,3}$

\section{Data Sources and Systematic Literature Review}

A medical librarian developed searches to identify studies that compared the survival after CABG using the RA and the SVG. Ovid's version of MEDLINE (In-Process \& Other Non-Indexed Citations and Ovid MEDLINE 1946 to Present), Ovid EMBASE (1974 to present), and The Cochrane Library (Wiley) were searched. Searches used subject headings and keywords for the following terms: "radial artery graft," "coronary artery bypass," "saphenous vein graft," and "internal mammary-coronary artery anastomosis." The full search strategy for Ovid MEDLINE is available in the Appendix 1. There were no publication date restrictions.

The inclusion criteria were English-language full-length articles, follow-up $>30$ days, direct comparison of survival of patient receiving the RA and the SVG, and isolated CABG. In addition, we handsearched recent meta-analyses and reviews on this topic for potential additional studies. In case of overlapping studies or studies from the same or overlapping cohorts reporting different outcomes, the largest series was included for each outcome. Studies in which additional arterial grafts were used in addition to the RA or that compared multiple arterial revascularization strategies were excluded unless it was possible to extract specific data of the subgroups who received only the RA or the SVG.

\section{Data Extraction and Quality Assessment}

Data extraction was performed independently by 2 investigators (A.A. and M.K.). In case of discrepancies, they were resolved by consultation with the first and senior author. The following variables were included: study demographics (sample size, number of centers, publication year, study period, design, and country), patient demographics and comorbidities in the unmatched and eventually matched population (age, sex, diabetes, ejection fraction, chronic obstructive pulmonary disease, and percentage of RA target vessel stenosis), and details of the surgical procedure.
The quality of the included observational studies was assessed using The Risk Of Bias In Non-randomized Studies-of Interventions assessment tool $^{4}$ and the included RCTs were assessed using the Cochrane Collaboration's Risk of Bias tool. ${ }^{5}$

\section{Outcomes}

The primary outcome was all-cause long-term mortality. The secondary outcomes were perioperative (30 days or in-hospital) mortality, perioperative myocardial infarction (MI), and stroke, follow-up MI, and repeat revascularization.

\section{Data Synthesis and Analysis}

The efficacies of RA versus SVG were compared directly in pairwise random effects meta-analyses by pooling data from the included studies using "meta" and "metafor" packages ${ }^{6,7}$ in R (version 3.3.3, R Project; R Foundation for Statistical Computing, Vienna, Austria). We pooled the short-term binary outcomes using odds ratio (OR) with $95 \%$ confidence interval (CI) using the generic inverse variance method. ${ }^{8}$ To account for potentially different follow-up durations between the groups, late outcomes were analyzed using the natural logarithm of the incident rate ratio (IRR, the ie, number of deaths per population at-risk per unit time). We estimated the IRR through several means depending on the available study data. When hazard ratios (HRs) were provided, we took the natural logarithm of the HR; the standard error was derived from the $95 \% \mathrm{CI}$ or $\log \operatorname{rank} P$ value. ${ }^{9}$ When HRs were not reported, we estimated IRR through either (1) the Kaplan-Meier curves using GetData Graph Digitizer software 2.26 (http://getdata-graph-digitizer.com/) or (2) the reported events and accumulated group-specific person-years of follow-up as previously described. ${ }^{10-12}$ When differential follow up durations by group were not provided, relative risk was used. For two studies (Yoo 2012 and RSVP) ${ }^{13,14}$ individual patients' data were used. Details of IRR calculation for the primary outcome are provided in Table $E 1^{13-24}$ in Appendix 1.

In addition, for the 9 studies that provided Kaplan-Meier curves for long-term survival (Benedetto and Codispoti 2013, Cohen and colleagues 2001, Lin and colleagues 2013, Locker and colleagues 2013, Petrovic and colleagues 2015, Santarpino and colleagues 2010, Schwann and colleagues 2015, RAPCO, Stand-in-Y), ${ }^{15-23}$ individual patient survival data were reconstructed using an iterative algorithm applied to solve the Kaplan-Meier equations that were originally used to produce the published graphs. This algorithm uses digitized Kaplan-Meier curve data to find numerical solutions to the inverted Kaplan-Meier equation. ${ }^{25}$ The algorithm assumes constant censoring. The reconstructed patient survival data were then aggregated to form combined survival curves.

Heterogeneity was reported as low $\left(\mathrm{I}^{2}=0 \%-25 \%\right)$, moderate $\left(\mathrm{I}^{2}=26 \%-50 \%\right)$, high $\left(\mathrm{I}^{2}>50 \%\right)$, consistent with guidelines. ${ }^{26}$ Publication bias was assessed visually by funnel plot and quantitatively by the Egger test. Crude outcomes were calculated by aggregating crude numbers of events from the individual studies. The SVG graft group was used as the reference group in all the analyses. Statistical significance was assumed for $P<.05$.

\section{Sensitivity Analyses}

Subgroup analysis was used to compare RCTs and observational studies for the primary outcome. A leave-one-out analysis was performed to examine the impact of individual studies on the robustness of the primary and secondary outcomes. Univariate meta-regression for the primary outcome was performed for of age, sex, diabetes, left ventricular function, and percentage of RA target vessel stenosis. The same meta-regression models were also applied for the differences between the RA and SVG arm in the unmatched population to test for potential unmatched confounders related to treatment allocation bias (see Appendix 1). As an 
TABLE 1. Demographics of the included studies (matched groups are considered in case of observational studies)

\begin{tabular}{|c|c|c|c|c|c|c|c|}
\hline Study & Arm & Age, $y$, mean \pm SD & Female, n (\%) & DM, n (\%) & $\mathbf{E F}$, mean $\pm \mathrm{SD}$ & COPD, n (\%) & RA TVS \\
\hline \multirow[t]{2}{*}{ Benedetto and Codispoti, $2013^{15}$} & RA & $64 \pm 10$ & $178(22)$ & $82(10.1)$ & $\mathrm{NR}^{*}$ & $92(11.4)$ & NR \\
\hline & SVG & $65 \pm 10$ & $157(19.4)$ & $98(12.1)$ & $\mathrm{NR}^{*}$ & $83(10.3)$ & \\
\hline \multirow[t]{2}{*}{ Cohen et al, $2001^{16}$} & RA & $60.7 \pm 8.8$ & $76(15.9)$ & $160(33.5)$ & NR & $23(4.8)$ & NR \\
\hline & SVG & $61.2 \pm 8.7$ & $152(15.9)$ & $238(24.9)$ & NR & $40(4.2)$ & \\
\hline \multirow[t]{2}{*}{ Goldman et al, $2011^{24}$} & RA & $61 \pm 8$ & $1(1)$ & $154(42)$ & NR & NR & $>70 \%$ \\
\hline & SVG & $62 \pm 8$ & $5(1)$ & $153(42)$ & NR & NR & \\
\hline \multirow[t]{2}{*}{ Lin et al, $2013^{17}$} & RA & $70.6 \pm 8.7$ & $79(30.4)$ & $101(38.8)$ & $53.6 \pm 13.5$ & $33(12.7)$ & NR \\
\hline & SVG & $70.9 \pm 9.8$ & $77(29.4)$ & $91(33.5)$ & $53.3 \pm 15.6$ & $39(15)$ & \\
\hline \multirow[t]{2}{*}{ Locker et al, $2013^{18}$} & RA & NR & NR & NR & NR & NR & NR \\
\hline & SVG & $59 \pm 10$ & $187(16.2)$ & $221(19.2)$ & $58 \pm 13$ & $86(7.5)$ & \\
\hline \multirow[t]{2}{*}{ Petrovic et al, $2015^{19}$} & RA & $56.3 \pm 6.1$ & $27(27)$ & $39(39)$ & $48.8 \pm 10.7$ & $9(9)$ & $\geq 80 \%$ \\
\hline & SVG & $57.1 \pm 6.5$ & $27(27)$ & $43(43)$ & $48 \pm 10.8$ & $8(8)$ & \\
\hline \multirow[t]{2}{*}{ Santarpino et al, $2010^{20}$} & RA & NR & NR & NR & NR & NR & $>80 \%$ \\
\hline & SVG & NR & NR & NR & NR & NR & \\
\hline \multirow[t]{2}{*}{ Schwann et al, $2015^{21}$} & RA & 62.7 & $803(27)$ & $1107(37.3)$ & 44.7 & $605(20.4)$ & NR \\
\hline & SVG & 62.7 & $780(26.3)$ & $1132(38.1)$ & 44.7 & $577(19.5)$ & \\
\hline \multirow[t]{2}{*}{ Tranbaugh et al, $2010^{27}$} & RA & $60.8 \pm 8.1$ & $203(23.5)$ & $314(36.4)$ & $48.3 \pm 11.8$ & 187 (21.7) & $>70 \%$ \\
\hline & SVG & $60.8 \pm 9.2$ & $185(22.5)$ & $332(38.3)$ & $47.7 \pm 13.2$ & $173(20.1)$ & \\
\hline \multirow[t]{2}{*}{ RAPCO (Hayward et al, 2008) 22} & RA & $72.9(62.3-83.5) \dagger$ & $10(14)$ & $27(37)$ & $\mathrm{NR}^{*}$ & NR & $\geq 70 \%$ \\
\hline & SVG & $73.2(64.0-82.4)$ & $13(16)$ & $37(46)$ & $\mathrm{NR}^{*}$ & NR & \\
\hline \multirow[t]{2}{*}{ Stand-in-Y (Nasso et al, 2009) } & RA & $70.5 \pm 3.1$ & $88(43.1)$ & $74(36.1)$ & $\mathrm{NR}^{*}$ & $58(28.2)$ & $\geq 70 \%$ \\
\hline & SVG & $69.7 \pm 3.5$ & 85 (41.6) & $78(38.1)$ & NR* & $57(27.7)$ & \\
\hline \multirow[t]{2}{*}{ Yoo et al, $2012^{13}$} & RA & $72.7 \pm 3.2$ & $18(51.4)$ & $15(42.9)$ & $\mathrm{NR}^{*}$ & NR & NR \\
\hline & SVG & $74.6 \pm 3.8$ & $11(44.0)$ & $13(52.0)$ & $\mathrm{NR}^{*}$ & NR & \\
\hline \multirow[t]{2}{*}{ RSVP (Collins et al, 2008) ${ }^{14}$} & RA & $58 \pm 6$ & $3(4)$ & $15(18)$ & NR & NR & $\geq 70 \%$ \\
\hline & SVG & $59 \pm 7$ & $2(3)$ & $10(17)$ & NR & NR & \\
\hline \multirow[t]{2}{*}{ Muneretto et al, $2004^{28}$} & RA & $77.3 \pm 3$ & $35(43.7)$ & $39(48.7)$ & NR & NR & $\geq 70 \%$ \\
\hline & SVG & $76.8 \pm 2$ & $37(46.2)$ & $36(45.0)$ & NR & NR & \\
\hline
\end{tabular}

$S D$, Standard deviation; $D M$, diabetes mellitus; $E F$, ejection fraction; $C O P D$, chronic obstructive pulmonary disease; RA, radial artery; TVS, target vessel stenosis; $N R$, not reported; $S V G$, saphenous vein graft. *EF reported as categories. †Median (interquartile range).

exploratory analysis, the same meta-regression model was also applied to operative mortality (see Appendix 1).

\section{RESULTS}

Among the 1201 screened articles, a total of 14 studies $^{13-24,27,28}$ (20,931 patients; $6671 \mathrm{RA}$ and 14,260 SVG) were included (7 RCTs $[\mathrm{n}=1924]$ and 7 observational studies $[\mathrm{n}=19,007$ patients $])$. The weighted mean follow-up was 6.6 years (Figure E1 in Appendix 1).

Four of the 14 studies were multicenter. Three studies were from the United States, 2 each from Italy and the United Kingdom, and 1 each from Canada, Korea, and Serbia. Demographics of the included studies are shown in Tables 1 and 2 and Table E2 in Appendix 1.

The Risk Of Bias In Non-randomized Studies-of Interventions assessment tool (version for cohort-type studies) ${ }^{4}$ and Cochrane Collaboration's Tool for RCTs are shown in the Online Data Supplement and Table E3 in Appendix 1, respectively. All observational studies included were matched or adjusted and were of high quality and low risk of bias. The RCTs were also found to be of low risk of bias.

The number of patients in the individual studies ranged from 35 to 4404 patients in the RA group and from 25 to 8069 in the SVG group. The mean age ranged from 56.3 to 77.3 years in the RA group and from 57.1 to 76.8 in the SVG group. The majority of patients were male, with female patients ranging from $1 \%$ to $51.4 \%$ in the RA group and from $1 \%$ to $46.2 \%$ in the SVG group. Most patients had normal or low-normal ejection fraction (range $44.7 \%-58 \%$ ).

Long-term mortality, repeat revascularization, and MI were reported in 12, 6, and 6 studies respectively $(19,046,1769$, and 1692 patients). For short-term outcomes, mortality was 
TABLE 2. Demographics of the included studies: Part 2

\begin{tabular}{|c|c|c|c|c|c|c|c|c|c|c|c|}
\hline Study & Type & Center & Period & $\begin{array}{c}\text { UNM } \\
\text { RA }\end{array}$ & $\begin{array}{l}\text { UNM } \\
\text { SVG }\end{array}$ & $\begin{array}{l}\text { UNM } \\
\text { Total }\end{array}$ & $\begin{array}{c}\text { MAT } \\
\text { RA }\end{array}$ & $\begin{array}{l}\text { MAT } \\
\text { SVG }\end{array}$ & $\begin{array}{l}\text { MAT } \\
\text { Total }\end{array}$ & $\begin{array}{c}\text { FU, } \\
\text { y mean } \pm \mathrm{SD}\end{array}$ & $\begin{array}{l}\text { Max } \\
\text { FU, y }\end{array}$ \\
\hline $\begin{array}{l}\text { Benedetto and } \\
\text { Codispoti, } \\
2013^{15}\end{array}$ & Obs. & $\begin{array}{l}\text { Papworth Hospital, } \\
\text { Cambridge, England }\end{array}$ & 1996-2012 & 936 & 8069 & 9005 & 809 & 809 & 1618 & $6.4 \pm 3.6$ & 13.6 \\
\hline $\begin{array}{l}\text { Cohen et al, } \\
2001^{16}\end{array}$ & Obs. & $\begin{array}{r}\text { Sunnybrook and Women's } \\
\text { College Health Sciences } \\
\text { Centre, Toronto, Canada }\end{array}$ & 1994-1999 & 478 & 2369 & 2847 & 478 & 956 & 1434 & - & 3 \\
\hline $\begin{array}{l}\text { Goldman et al, } \\
2011^{24}\end{array}$ & RCT & Multicenter & 2003-2009 & 366 & 367 & 733 & - & - & - & - & 1 \\
\hline Lin et al, $2013^{17}$ & Obs. & $\begin{array}{l}\text { Cedars-Sinai Medical Center } \\
\text { in Los Angeles, California }\end{array}$ & $1997-2001$ & - & - & - & 260 & 260 & 520 & $9.4(5.7-11.9)^{*}$ & 12 \\
\hline $\begin{array}{l}\text { Locker et al, } \\
2013^{18}\end{array}$ & Obs. & $\begin{array}{l}\text { Mayo Clinic, Rochester, } \\
\text { Minn }\end{array}$ & 1993-2009 & 168 & 7281 & 7449 & - & - & - & $7.6 \pm 4.6$ & 18.3 \\
\hline $\begin{array}{l}\text { Petrovic et al, } \\
2015^{19}\end{array}$ & RCT & $\begin{array}{l}\text { Belgrade University School of } \\
\text { Medicine, Belgrade, Serbia }\end{array}$ & 2001-2003 & 100 & 100 & 200 & - & - & - & - & 8 \\
\hline $\begin{array}{l}\text { Santarpino } \\
\text { et al, } 2010^{20}\end{array}$ & Obs. & $\begin{array}{l}\text { Magna Graecia University of } \\
\text { Catanzaro, Italy }\end{array}$ & 2003-2007 & 150 & 180 & 330 & - & - & - & $3.17 \pm 0.07$ & 4.8 \\
\hline $\begin{array}{l}\text { Schwann et al, } \\
2015^{21}\end{array}$ & Obs. & Multicenter & 1994-2011 & 4404 & 6709 & 11,261 & 2966 & 2966 & 5932 & - & 15 \\
\hline $\begin{array}{l}\text { Tranbaugh } \\
\text { et al, } 2010^{27}\end{array}$ & Obs. & $\begin{array}{l}\text { Beth Israel Medical Center, } \\
\text { New York, NY }\end{array}$ & 1995-2009 & 1560 & 2711 & 4271 & 862 & 862 & 1724 & $7.7(0.1-13.8)^{*}$ & 14 \\
\hline $\begin{array}{l}\text { RAPCO } \\
\qquad \begin{array}{l}\text { (Hayward } \\
\text { et al, 2008) }\end{array}\end{array}$ & RCT & $\begin{array}{l}\text { Austin Hospital, Victoria, } \\
\text { Australia }\end{array}$ & 1996-2002 & 73 & 80 & 153 & - & - & - & 6.2 & 10.8 \\
\hline $\begin{array}{l}\text { Stand-in-Y } \\
\quad(\text { Nasso } \\
\quad \text { et al, 2009) })^{23}\end{array}$ & RCT & $\begin{array}{l}\text { Anthea Hospital, Bari, Italy; and } \\
\text { Villa Azzurra Hospital, } \\
\text { Rapallo, Italy }\end{array}$ & 2003-2006 & 202 & 202 & 404 & - & - & - & $2.0 \pm 0.8$ & - \\
\hline $\begin{array}{l}\text { Yoo et al, } \\
2012^{13}\end{array}$ & RCT & $\begin{array}{l}\text { Severance Hospital, } \\
\text { Yonsei University } \\
\text { Health System, } \\
\text { Seoul, Korea }\end{array}$ & 2008-2009 & 35 & 25 & 60 & - & - & - & 0.7 & - \\
\hline $\begin{array}{l}\text { RSVP (Collins } \\
\text { et al, 2008) }{ }^{14}\end{array}$ & RCT & $\begin{array}{l}\text { Royal Brompton and Harefield } \\
\text { NHS Trust, London, UK }\end{array}$ & $1998-2000$ & 82 & 60 & 142 & - & - & - & 5 & - \\
\hline $\begin{array}{l}\text { Muneretto } \\
\text { et al, } 2004^{28}\end{array}$ & RCT & $\begin{array}{l}\text { University of Brescia Medical } \\
\text { School, Brescia, Italy }\end{array}$ & $2000-2002$ & 80 & 80 & 160 & - & - & - & $1.3 \pm 0.3$ & - \\
\hline
\end{tabular}

$\overline{U N M}$, Unmatched group; $R A$, radial artery; $S V G$, saphenous vein graft; $M A T$, matched group; $F U$, follow-up; $S D$, standard deviation; $O b s$., observational study; $R C T$, randomized controlled trial. *Median and interquartile range.

reported in 11 studies (11,533 patients), stroke in 7 studies (3883 patients) and MI in 7 studies (6574 patients).

\section{Primary Outcome}

At a weighted mean follow-up of 6.6 years, mortality was $24.5 \%$ in RA group versus $34.2 \%$ in SVG group (IRR, 0.74; 95\% CI, 0.63-0.87, $P<.001$ ) (Figure 1). Reconstructed Kaplan-Meier overall survival for RA versus SVG among included studies is shown in Figure E2 and Table E4 in Appendix 1.

Leave-one-out analysis supported the robustness of this finding (Figure E3, A, in Appendix 1). Funnel plot showed no publication bias (Egger test intercept was $-0.72 \pm 0.56, P=.23$, Figure E3, $B$, in Appendix 1).
Subgroup analysis based on the study type revealed lower mortality in RA compared with SVG in observational studies but not in RCTs (IRR 0.71; 95\% CI, 0.58- 0.87 and IRR, 0.88; 95\% CI, 0.60-1.31) respectively (Figure E4 in Appendix 1).

\section{Secondary Outcomes}

Operative mortality was $1.25 \%$ in RA group versus $1.33 \%$ in SVG group (OR, 0.93; 95\% CI, 0.68-1.28). No difference in perioperative $\mathrm{MI}$ or stroke was found (OR, 0.96; 95\% CI, 0.59-1.56 and OR, 0.70; 95\% CI, 0.43-1.13, respectively) (Figure E5 in Appendix 1).

No difference in follow-up MI or repeat revascularization was found between groups at a weighted mean follow-up of 


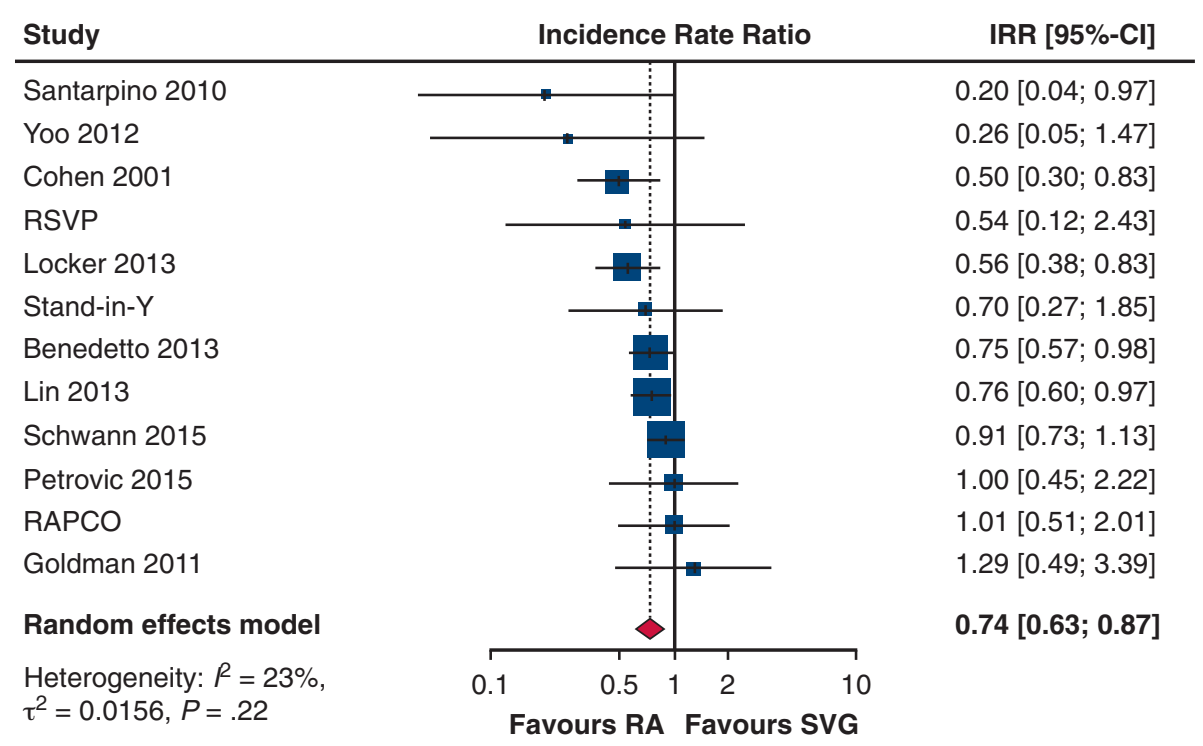

FIGURE 1. Forest plot for long-term mortality (expressed as incidence rate ratio [IRR]). CI, Confidence interval; $R A$, radial artery, $S V G$, saphenous vein graft.

3 and 2.8 years, respectively (IRR, $0.76 ; 95 \% \mathrm{CI}, 0.42-1.36$ and IRR, 0.68; 95\% CI, 0.42-1.09, Table 3; Figure 2). However, when excluding the VA trial (limited to 1-year follow-up) the RA was associated with a significantly lower risk of repeat revascularization (Figure E6 in Appendix 1).

\section{Meta-Regression}

The survival advantage for the RA was independent from age (beta $=0.005, P=.79$ ), percentage of females (beta $=0.005, P=.65$ ), diabetes mellitus (beta $=0.009$, $P=.15$ ), left ventricular ejection fraction (bet $\mathrm{a}=-0.04$, $P=.21)$, and RA target vessel stenosis severity (beta $=-0.06, P=.37$ ) (Figure E7 in Appendix 1). The results of the meta-regression model in the unmatched populations confirmed the results of the main analysis (Table E5 in Appendix 1). No effect of the explored variables on operative mortality was found (Table E6 in Appendix 1).

\section{DISCUSSION}

Together with the right internal thoracic artery, the RA is the most commonly used complementary arterial graft for
CABG. The easy accessibility, possibility of simultaneous harvesting with other arterial conduits, optimal caliber, and length make the RA an almost-ideal conduit for CABG. Compared with the right internal thoracic artery, the RA also has the additional advantage of easier technical manipulation without an increase in the risk of sternal complications. $^{29}$

The patency rate of the RA has been shown to be significantly better than that of the SVG at mid- and long-term follow-up. Two large angiographic randomized trials and several meta-analyses have in fact shown that the occlusion rate of SVG grafts is significantly greater than that of the RA, especially after the fourth postoperative year. ${ }^{1,14,30}$ In the angiographic comparison with the longest follow-up published to date, we have described a more than 2 -fold increase in the risk of graft occlusion at 20 years using the SVG instead of the RA as a conduit. ${ }^{31}$

Recently, in a pooled patient-level analysis of all the RCTs that have compared the 2 conduits we have reported a significantly lower risk of the composite of death, MI,

TABLE 3. Outcomes summary

\begin{tabular}{lccccc}
\hline \multicolumn{1}{c}{ Outcomes } & Number of patients (mean follow-up) & Number of studies & $\begin{array}{c}\text { Point estimate* } \\
\mathbf{9 5} \% \mathbf{C I}\end{array}$ & $\frac{\text { Overall effect }}{\boldsymbol{P} \text { value }}$ & $\frac{\text { Heterogeneity }}{\left(\mathbf{I}^{\mathbf{2}}, \boldsymbol{P} \text { value }\right)}$ \\
\hline Long-term mortality & $19,046(6.63 \mathrm{y})$ & 12 & $0.74(0.63-0.87)$ & $<.001$ & $23.1 \%, P=.22$ \\
Follow-up RR & $1769(2.84 \mathrm{y})$ & 6 & $0.68(0.42-1.09)$ & .11 & $12.6 \%, P=.33$ \\
Follow-up MI & $1769(2.99 \mathrm{y})$ & 6 & $0.76(0.42-1.36)$ & .35 & $0 \%, P=.94$ \\
Operative mortality & 11,533 & 11 & $0.93(0.68-1.28)$ & .67 & $0 \%, P=.93$ \\
Perioperative stroke & 3883 & 7 & $0.70(0.43-1.13)$ & .14 & $0 \%, P=.74$ \\
Perioperative MI & 6574 & 7 & $0.96(0.59-1.56)$ & .86 & $0 \%, P=.89$ \\
\hline
\end{tabular}

$C I$, Confidence interval; $R R$, repeated revascularization; $M I$, myocardial infarction. *Incidence rate ratio was used for long-term outcomes whereas odds ratio was used for perioperative outcomes. 


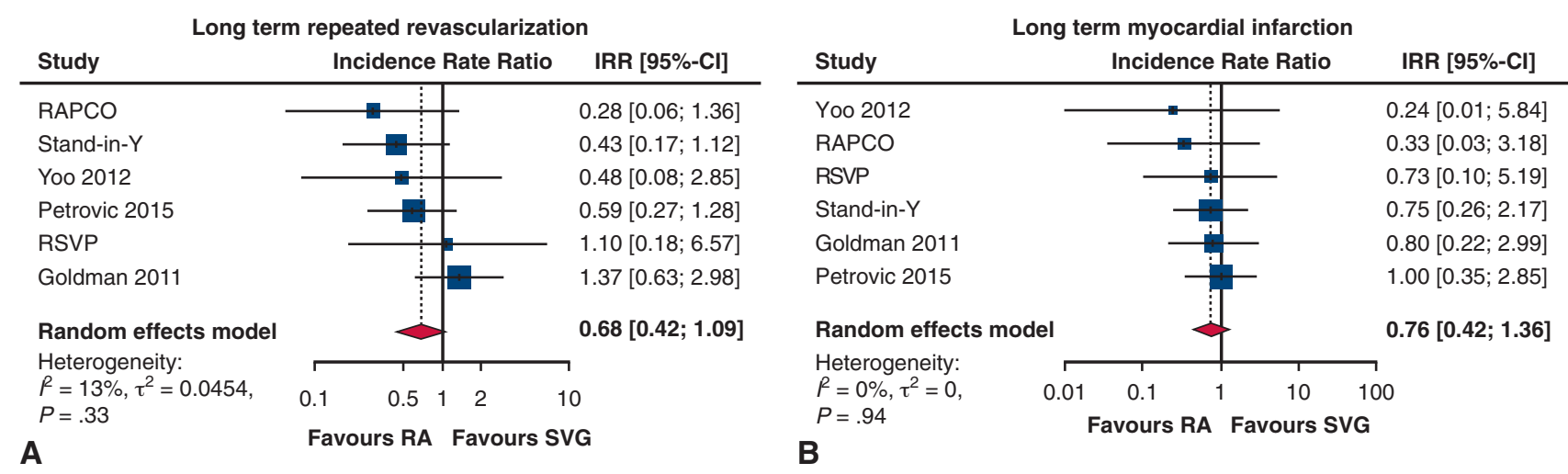

FIGURE 2. Forest plots of long-term secondary outcomes: A, Long-term repeat revascularization; B, long-term myocardial infarction (both expressed as incidence rate ratio $[I R R])$. $C I$, Confidence interval; $R A$, radial artery, $S V G$, saphenous vein graft.

and/or repeat revascularization 5 years after surgery. ${ }^{32}$ No statistically significant difference in mortality was found.

Regarding long-term survival, in the largest single-center observational study comparing the RA and the SVG, Schwann and colleagues ${ }^{21}$ reported on 11,261 patients and found significantly better survival at 15 years in the RA group. In a similar study on 8622 patients, Locker and colleagues ${ }^{18}$ reported a $44 \%$ reduction in the risk of death at late 7.6 years follow-up in patients who received an RA instead of SVG.

However, the published evidence on the clinical effect of using the RA for CABG is mainly derived single-center observational studies from institutions which are very experienced with the use of arterial conduits. Previously published meta-analyses have focused on RCTs and angiographic outcomes. Thus, to our knowledge, this is the first meta-analysis to estimate the clinical effect of using the RA for CABG including outcomes from RCTs and matched or adjusted observational studies. To circumvent issues in generalizability by including only singleinstitution studies, which can vary considerably based on local factors and experience with the RA, we included data from 14 RCTs and observational studies involving 20,931 patients in aggregate with a mean follow-up of 6.6 years. The key finding is that the use of the RA is associated with a significant reduction in mortality at follow-up without an increase in the operative mortality or morbidity. The beneficial effect of the use of the RA is independent of age, sex, diabetes status, and left ventricular function. The differences in results for the secondary outcomes between this meta-analysis and our previous analysis of individual patient data are due to the different inclusion criteria (only studies with a follow-up $>2$ years were included in our previous study) and in the statistical approach used for aggregate versus individual patient analyses.

\section{Limitations}

The results of this meta-analysis must be interpreted in the context of some important limitations. The inclusion of observational studies raises the possibility of bias from unmatched confounders due to treatment allocation by the operating surgeons. ${ }^{12}$ For this reason, we decided to limit our analysis to adjusted and matched observational studies, although we acknowledge that even the best matching techniques can be inadequate to minimize the effect of treatment allocation bias in studies of this type. It is important, and somewhat reassuring, to note that in our analysis, the patients' profile of the 2 arms in the unmatched population was very similar. It is possible that, as the use of the RA is generally perceived to be associated with less morbidity than bilateral internal thoracic artery, the confounders that we have described in studies comparing single and double internal thoracic arteries ${ }^{12}$ are somewhat reduced in the studies comparing the RA and the SVG. In addition, we have used meta-regression to evaluate the variation of the results of the RA versus SVG comparison according to the difference in preoperative profile of the unmatched arms and found that the survival benefit associated with the RA was confirmed in every scenario.

This study shares the limitation of the analyses of aggregate data. There may be difference in surgical techniques, perioperative protocols, definition of nonfatal outcomes, and secondary prevention strategies among the included studies. However, only moderate heterogeneity was found across the different series, suggesting that these differences, if present, had only a marginal effect on the primary outcome. Finally, the analyses on repeat revascularization and late MI included only few studies and were very likely underpowered.

In conclusion, our analysis of the aggregated evidence comparing the RA and SVG for CABG showed that the use of the arterial conduit was associated with a statistically significant $26 \%$ relative reduction in the risk of death at a mean follow-up of 6.6 years without significant increase in the operative risk. Our results, combined with the large amount of evidence of better patency rate and clinical outcome for the RA compared with the SVG, suggests that the RA should be used in preference to the SVG at least 
in patients in whom it is technical appropriate and with long life expectancy.

\section{Webcast}

You can watch a Webcast of this AATS meeting presentation by going to: https://aats.blob.core.windows.net/media/18Apr 30/28ABC $\%$ 20Controversies $\% 20$ in $\% 20 \mathrm{CABG} / \mathrm{S} 65 \% 20$ \%20Part\%201/S65_1_webcast_020448540.mp4.

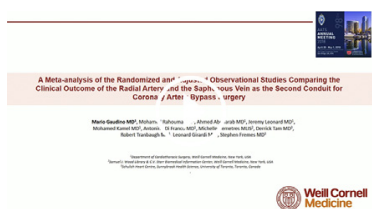

\section{Conflict of Interest Statement}

Authors have nothing to disclose with regard to commercial support.

\section{References}

1. Benedetto U, Raja SG, Albanese A, Amrani M, Biondi-Zoccai G, Frati G. Searching for the second best graft for coronary artery bypass surgery: a network meta-analysis of randomized controlled trials. Eur J Cardiothorac Surg. 2015; 47:59-65; discussion 65.

2. Hutton B, Salanti G, Caldwell DM, Chaimani A, Schmid CH, Cameron C, et al. The PRISMA extension statement for reporting of systematic reviews incorporating network meta-analyses of health care interventions: checklist and explanations. Ann Intern Med. 2015;162:777-84.

3. Liberati A, Altman DG, Tetzlaff J, Mulrow C, Gøtzsche PC, Ioannidis JPA, et al. The PRISMA statement for reporting systematic reviews and meta-analyses of studies that evaluate health care interventions: explanation and elaboration. PLOS Med. 2009;6:e1000100.

4. Sterne JA, Hernán MA, Reeves BC, Savović J, Berkman ND, Viswanathan M, et al. ROBINS-I: a tool for assessing risk of bias in non-randomised studies of interventions. BMJ. 2016;355.

5. Higgins JPT, Altman DG, Gøtzsche PC, Jüni P, Moher D, Oxman AD, et al. The Cochrane Collaboration's tool for assessing risk of bias in randomised trials. BMJ. 2011;343:d5928.

6. Schwarzer G, Carpenter JR, Rücker G. An introduction to meta-analysis in R. In: Schwarzer G, Carpenter JR, Rücker G, eds. Meta-analysis with R. Basel. Switzerland: Springer International Publishing; 2015:3-17.

7. Viechtbauer W. Conducting meta-analyses in $\mathrm{R}$ with the metafor package. J Stat Software. 2010;36(3). Available at: https://www.jstatsoft.org/article/view/v036i03. Accessed February 10, 2018.

8. DerSimonian R, Laird N. Meta-analysis in clinical trials. Control Clin Trials. 1986:7:177-88.

9. Parmar MK, Torri V, Stewart L. Extracting summary statistics to perform meta-analyses of the published literature for survival endpoints. Stat Med. 1998; 17:2815-34

10. Yanagawa B, Verma S, Jüni P, Tam DY, Mazine A, Puskas JD, et al. A systematic review and meta-analysis of in situ versus composite bilateral internal thoracic artery grafting. J Thorac Cardiovasc Surg. 2017;153:1108-16.e16.

11. Tierney JF, Stewart LA, Ghersi D, Burdett S, Sydes MR. Practical methods for incorporating summary time-to-event data into meta-analysis. Trials. 2007;8:16.

12. Gaudino M, Di Franco A, Rahouma M, Tam DY, Iannaccone M, Deb S, et al. Unmeasured confounders in observational studies comparing bilateral versus single internal thoracic artery for coronary artery bypass grafting: a meta-analysis. J Am Heart Assoc. January 6, 2018 [Epub ahead of print].
13. Song S-W, Sul S-Y, Lee H-J, Yoo K-J. Comparison of the radial artery and saphenous vein as composite grafts in off-pump coronary artery bypass grafting in elderly patients: a randomized controlled trial. Korean Circ J. 2012;42:107-12.

14. Collins P, Webb CM, Chong CF, Moat NE. Radial artery versus saphenous vein patency randomized trial: five-year angiographic follow-up. Circulation. 2008; 117:2859-64.

15. Benedetto U, Codispoti M. Age cutoff for the loss of survival benefit from use of radial artery in coronary artery bypass grafting. J Thorac Cardiovasc Surg. 2013 146:1078-85.

16. Cohen G, Tamariz MG, Sever JY, Liaghati N, Guru V, Christakis GT, et al The radial artery versus the saphenous vein graft in contemporary CABG a case-matched study. Ann Thorac Surg. 2001;71:180-5; discussion 185-6.

17. Lin J, Cheng W, Czer LS, De Robertis MA, Mirocha J, Ruzza A, et al. Coronary artery bypass graft surgery using the radial artery as a secondary conduit improves patient survival. J Am Heart Assoc. 2013;2:e000266.

18. Locker C, Schaff HV, Dearani JA, Daly RC. Improved late survival with arterial revascularization. Ann Cardiothorac Surg. 2013;2:467-74.

19. Petrovic I, Nezic D, Peric M, Milojevic P, Djokic O, Kosevic D, et al Radial artery vs saphenous vein graft used as the second conduit for surgical myocardial revascularization: long-term clinical follow-up. J Cardiothorac Surg. 2015;10:127.

20. Santarpino G, Onorati F, Cristodoro L, Scalas C, Mastroroberto P, Renzulli A Radial artery graft flowmetry is better than saphenous vein on postero-lateral wall. Int J Cardiol. 2010;143:158-64.

21. Schwann TA, Al-Shaar L, Tranbaugh RF, Dimitrova KR, Hoffman DM, Geller CM, et al. Multi versus single arterial coronary bypass graft surgery across the ejection fraction spectrum. Ann Thorac Surg. 2015;100:810-7; discussion 817-18.

22. Hayward PAR, Hare DL, Gordon I, Buxton BF. Effect of radial artery or saphenous vein conduit for the second graft on 6-year clinical outcome after coronary artery bypass grafting. Results of a randomised trial. Eur J Cardio-Thorac Surg. 2008;34:113-7.

23. Nasso G, Coppola R, Bonifazi R, Piancone F, Bozzetti G, Speziale G. Arteria revascularization in primary coronary artery bypass grafting: direct comparison of 4 strategies-results of the Stand-in-Y Mammary Study. J Thorac Cardiovasc Surg. 2009; 137:1093-100.

24. Goldman S, Sethi GK, Holman W, Thai H, McFalls E, Ward HB, et al Radial artery grafts vs saphenous vein grafts in coronary artery bypass surgery: a randomized trial. JAMA. 2011;305:167-74.

25. Guyot P, Ades A, Ouwens MJ, Welton NJ. Enhanced secondary analysis of survival data: reconstructing the data from published Kaplan-Meier survival curves. BMC Med Res Methodol. 2012;12:9.

26. Higgins JPT, Thompson SG, Deeks JJ, Altman DG. Measuring inconsistency in meta-analyses. BMJ. 2003;327:557-60.

27. Tranbaugh RF, Dimitrova KR, Friedmann P, Geller CM, Harris LJ, Stelzer P, et al. Radial artery conduits improve long-term survival after coronary artery bypass grafting. Ann Thorac Surg. 2010;90:1165-72.

28. Muneretto C, Bisleri G, Negri A, Manfredi J, Carone E, Morgan JA, et al. Lef internal thoracic artery-radial artery composite grafts as the technique of choice for myocardial revascularization in elderly patients: a prospective randomized evaluation. J Thorac Cardiovasc Surg. 2004;127:179-84.

29. Gaudino M, Taggart D, Suma H, Puskas JD, Crea F, Massetti M. The choice of conduits in coronary artery bypass surgery. J Am Coll Cardiol. 2015;66:1729-37.

30. Deb S, Cohen EA, Singh SK, Une D, Laupacis A, Fremes SE, RAPS Investigators. Radial artery and saphenous vein patency more than 5 years after coronary artery bypass surgery: results from RAPS (Radial Artery Patency Study). J Am Coll Cardiol. 2012;60:28-35.

31. Gaudino M, Tondi P, Benedetto U, Milazzo V, Flore R, Glieca F, et al. Radia artery as a coronary artery bypass conduit: 20-year results. J Am Coll Cardiol. 2016;68:603-10.

32. Gaudino M, Benedetto U, Fremes S, Biondi-Zoccai G, Sedrakyan A, Puskas JD et al; RADIAL Investigators. Radial-artery or saphenous-vein grafts in coronary-artery bypass surgery. N Engl J Med. 2018;378:2069-77.

Key Words: radial artery, saphenous vein, coronary artery bypass surgery, CABG, meta-analysis 


\section{APPENDIX 1}

Full search strategy

Ovid MEDLINE Epub Ahead of Print, in-process and other non-indexed citations,

Ovid MEDLINE Daily and Ovid MEDLINE: 1946 to Present (Searched on 08/22/2017)

\begin{tabular}{|c|c|}
\hline Line \# & | Search term \\
\hline 1 & Radial Artery/tr [Transplantation] \\
\hline 2 & Radial Artery/ and (Transplantation/ or Transplants/) \\
\hline 3 & $(($ radial arter* or arteria radialis or radialis artery) and (transplant* or graft*)).tw. \\
\hline 4 & or/1-3 \\
\hline 5 & Coronary Artery Bypass/ \\
\hline 6 & (aorta adj2 bypass).tw. \\
\hline 7 & CABG.tw. \\
\hline 8 & (aortic coronary bypass or aorticocoronary anastomosis).tw. \\
\hline 9 & (aorto coronary adj2 (bypass or graft)).tw. \\
\hline 10 & (aortocoronary adj2 (anastomosis or bypass or shunt or graft)).tw. \\
\hline 11 & (coronary adj2 (bypass or graft)).tw. \\
\hline 12 & $\begin{array}{l}\text { (Total arterial revascularization or total arterial revascularisation or Multiple arterial revascularization or multiple arterial } \\
\text { revascularisation).tw. }\end{array}$ \\
\hline 13 & or/5-12 \\
\hline 14 & Saphenous Vein/tr [Transplantation] \\
\hline 15 & Saphenous Vein/ and (Transplantation/ or Transplants/) \\
\hline 16 & $(($ Saphenous Vein* or SVG or saphena vein or saphenous venos system or vena saphena) and (transplant* or graft*)).tw. \\
\hline 17 & Internal Mammary-Coronary Artery Anastomosis/ \\
\hline 18 & $\begin{array}{l}\text { ((Right Internal Mammary Artery or RIMA or Coronary Internal Mammary Artery or arteria mammaria interna or arteria thoracica interna or } \\
\text { internal thoracic artery or mammary internal artery) and (transplant* or graft* or anastomosis)).tw. }\end{array}$ \\
\hline 19 & $\begin{array}{l}\text { (cardiac muscle revascularisation or cardiac muscle revascularization or coronary revascularisation or coronary revascularization or heart } \\
\text { muscle revascularisation or heart myocardium revascularisation or heart revascularisation or heart revascularization or internal mammary } \\
\text { arterial anastomosis or internal mammary arterial implantation or internal mammary artery anastomosis or internal mammary artery graft } \\
\text { or internal mammary artery implant or internal mammary artery implantation or internal mammary-coronary artery anastomosis or } \\
\text { myocardial revascularisation or myocardial revascularization or myocardium revascularisation or myocardium revascularization or } \\
\text { transmyocardial laser revascularisation or transmyocardial laser revascularization or vineberg operation).tw. }\end{array}$ \\
\hline 20 & or/14-19 \\
\hline 21 & 4 and 13 and 20 \\
\hline 22 & Editorial/ or Letter/ or Comment/ or Meeting abstract/ \\
\hline 23 & (conference paper or conference proceeding* or conference abstract* or meeting abstract or editorial or letter or comment).pt. \\
\hline 24 & 22 or 23 \\
\hline 25 & $21 \operatorname{not} 24$ \\
\hline 26 & limit 25 to English language \\
\hline
\end{tabular}




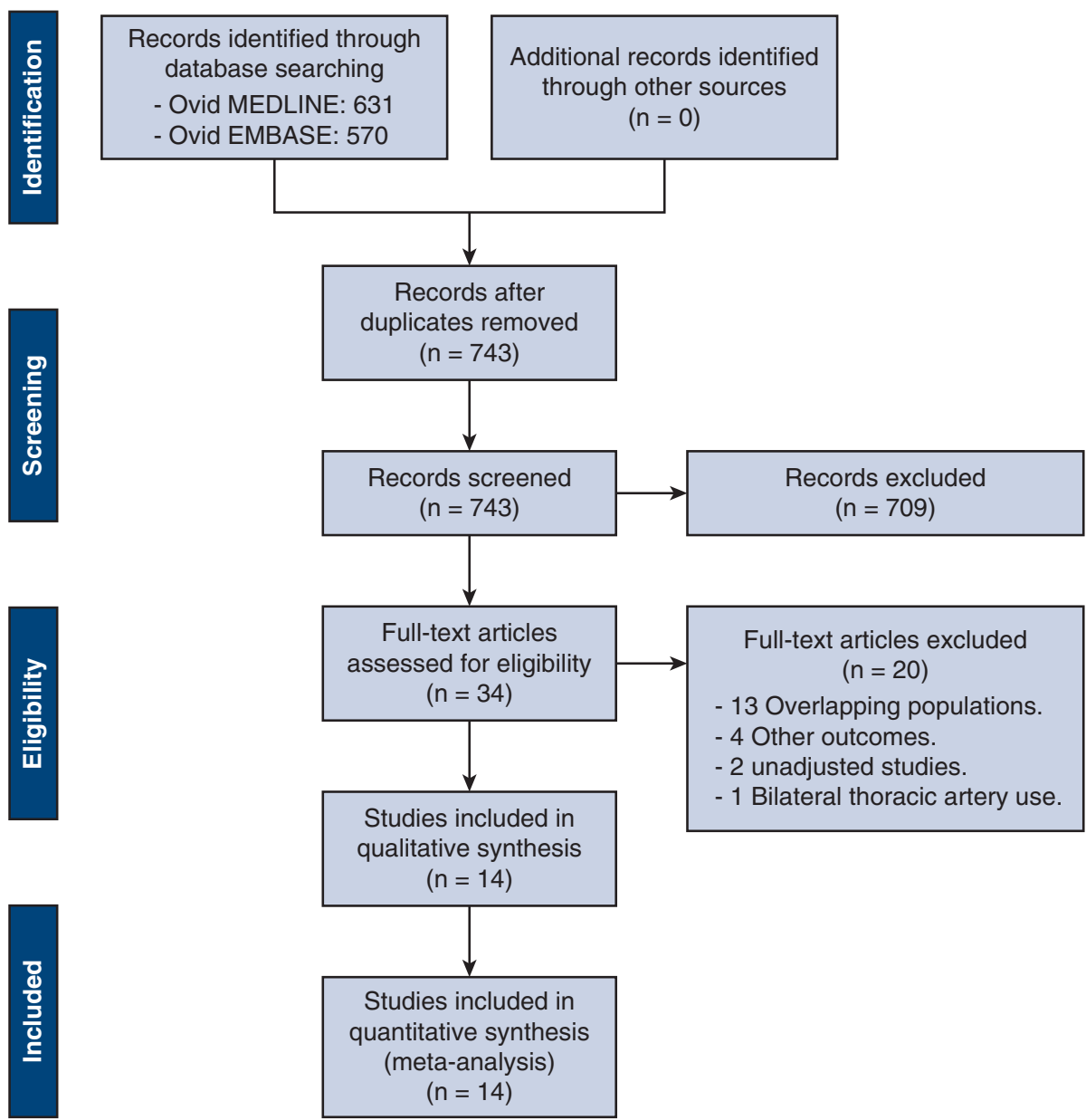

FIGURE E1. Preferred Reporting Items for Systematic Reviews and Meta-Analysis flow diagram. 


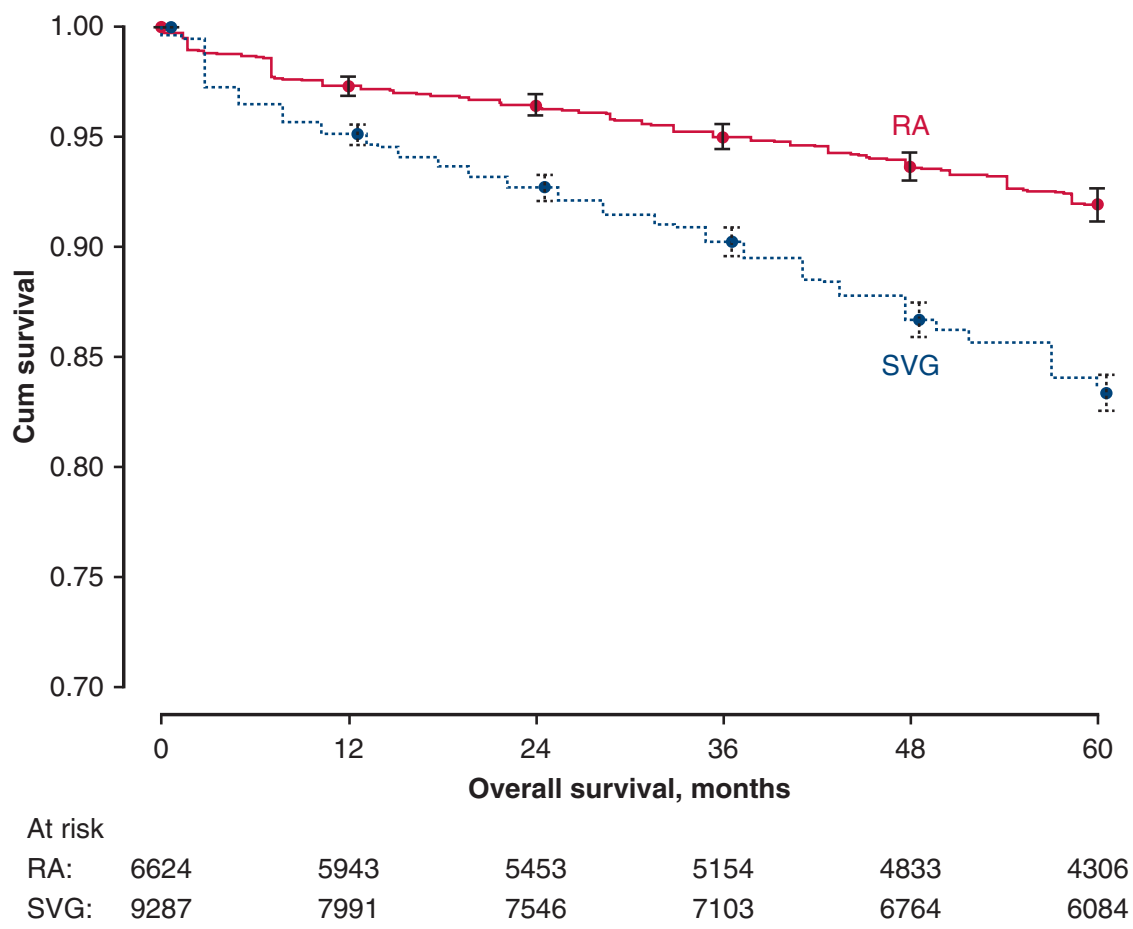

FIGURE E2. Reconstructed Kaplan-Meier overall survival for RA versus SVG among included studies with error bars denoting 95\% confidence intervals $(P<.001) . R A$, Radial artery; $S V G$, saphenous vein graft.

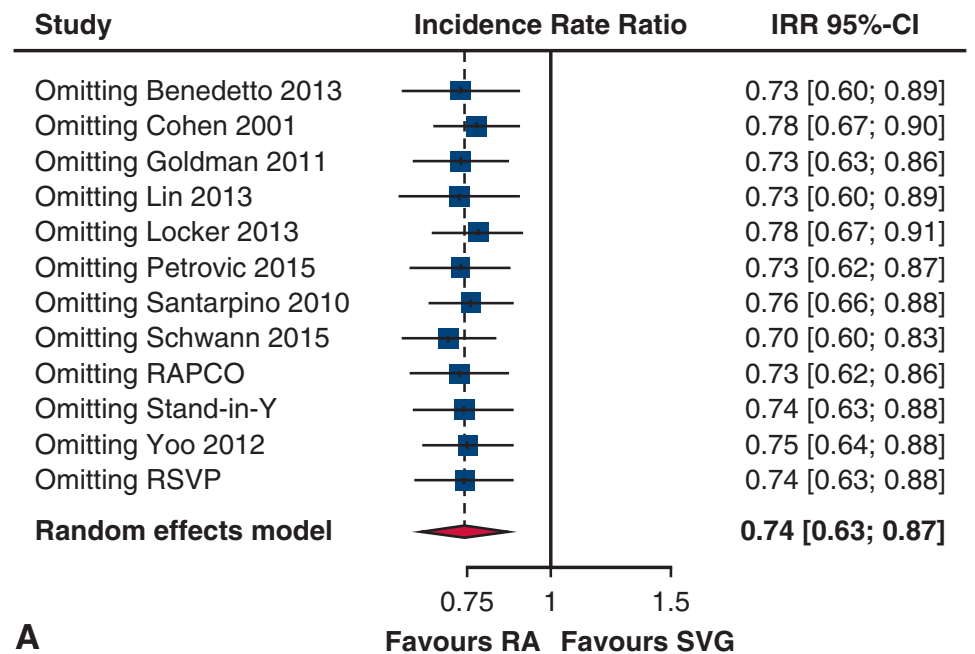

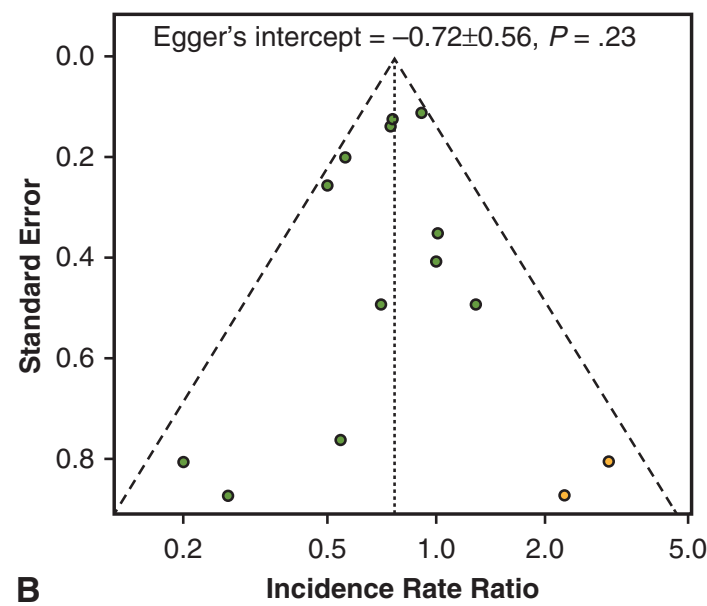

FIGURE E3. Primary outcomes: (A) Leave-one-out analysis and (B) Funnel plot with trim-and-fill method and Egger test results. IRR, Incidence rate ratio; $C I$, confidence interval; $R A$, radial artery; $S V G$, saphenous vein graft. 


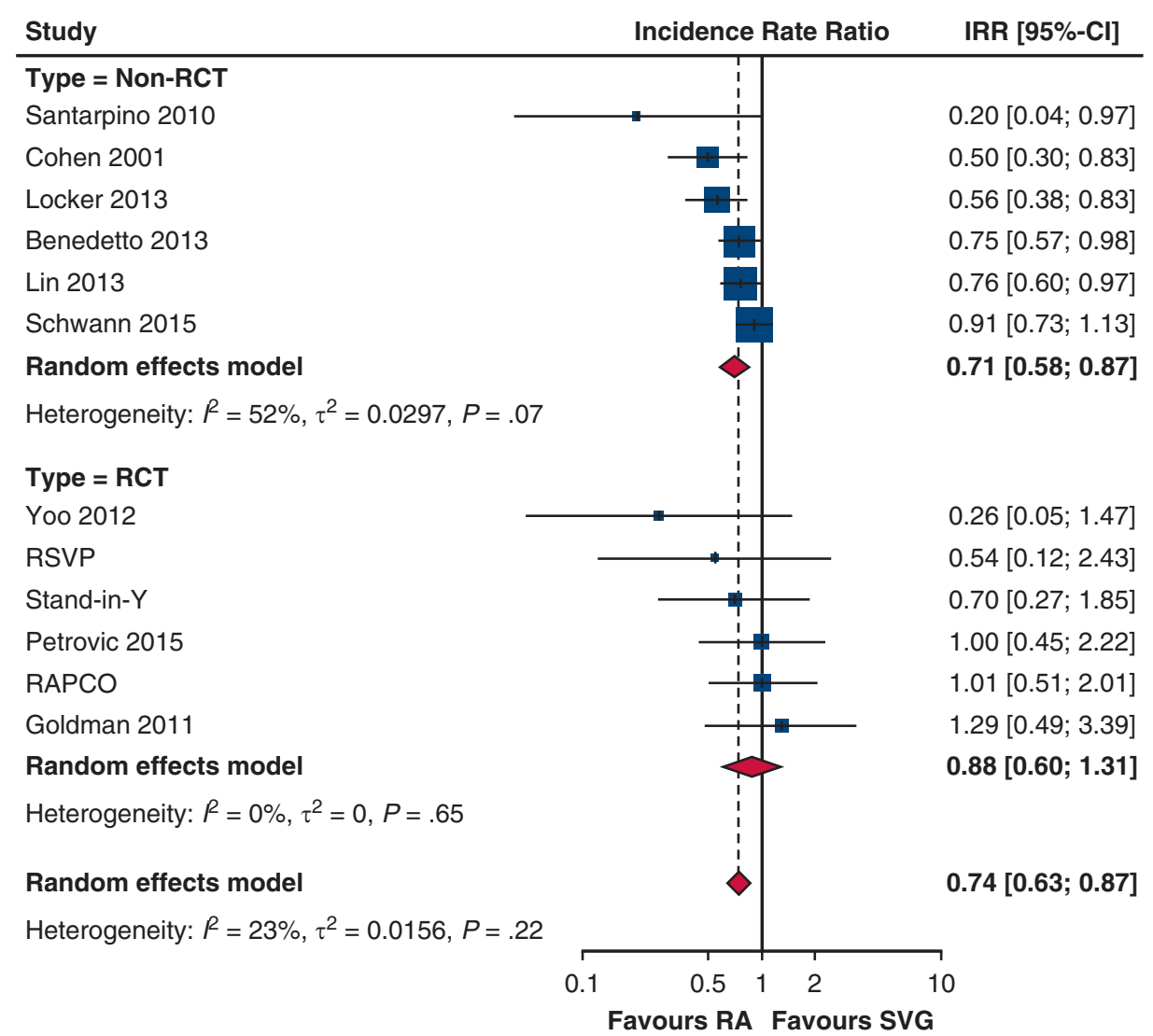

FIGURE E4. Forest plot of late mortality in RA versus SVG according to study type (non-RCT vs RCTs). IRR, Incidence rate ratio; $C I$, confidence interval; Non-RCTs, nonrandomized observational clinical trials; $R C T$, randomized clinical trials; $R A$, radial artery; $S V G$, saphenous vein graft. 


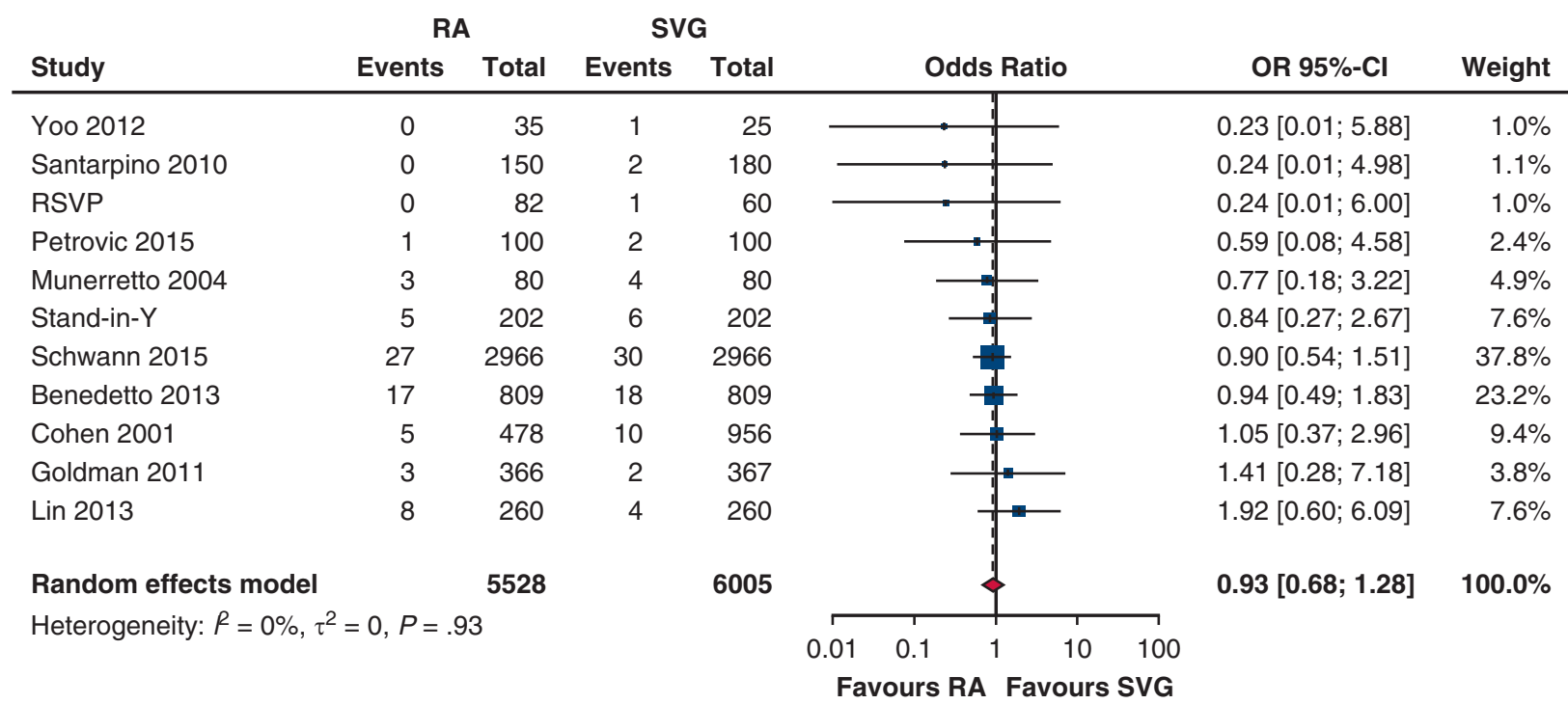

A

RA SVG

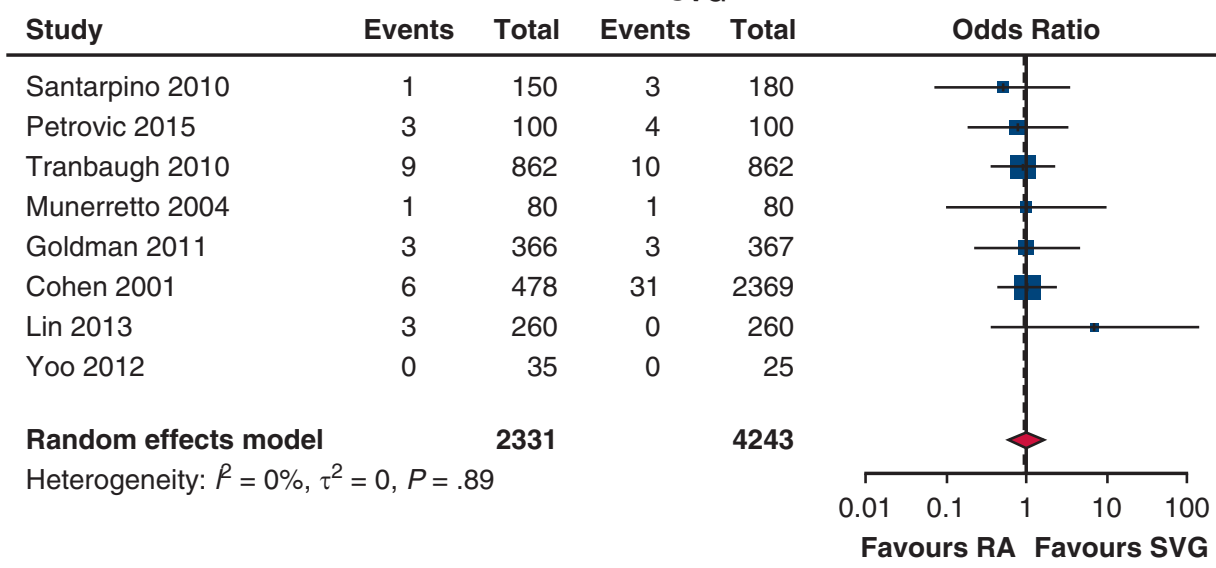

B

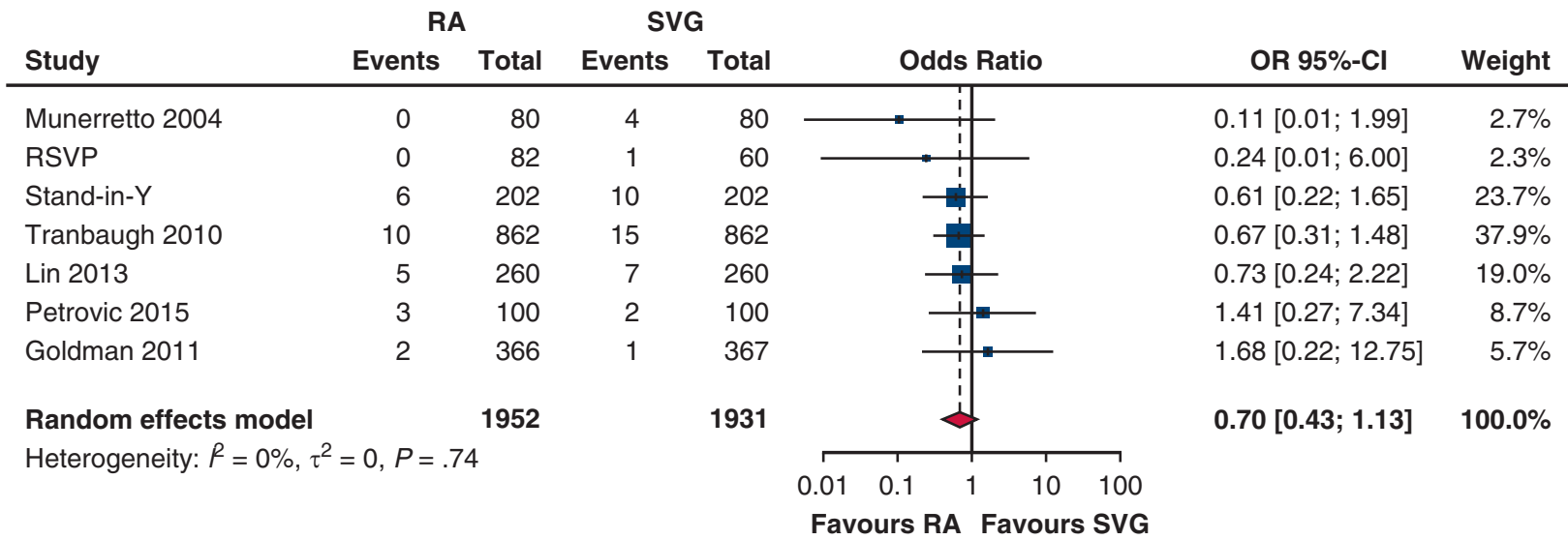

C

FIGURE E5. Forest plots for short term secondary outcomes: (A) operative mortality, (B) perioperative myocardial infarction and, (C) perioperative stroke (all expressed as OR). RA, Radial artery; $S V G$, saphenous vein graft; $O R$, odds ratio; $C I$, confidence interval. 


\begin{tabular}{|c|c|c|}
\hline Study & Incidence Rate Ratio & IRR 95\%-CI \\
\hline Omitting Goldman 2011 & & $0.51[0.31 ; 0.86]$ \\
\hline Omitting Petrovic 2015 & & $0.69[0.36 ; 1.32]$ \\
\hline Omitting RAPCO & & $0.74[0.46 ; 1.19]$ \\
\hline Omitting RSVP & & $0.64[0.37 ; 1.10]$ \\
\hline Omitting Stand-in-Y & & $0.76[0.45 ; 1.30]$ \\
\hline Omitting Yoo 2012 & - & $0.69[0.40 ; 1.19]$ \\
\hline \multirow[t]{2}{*}{ Random effects model } & - & $0.68[0.42 ; 1.09]$ \\
\hline & 0.5 & \\
\hline & Favours RA Favours S & \\
\hline
\end{tabular}

\begin{tabular}{|c|c|c|}
\hline Study & Incidence Rate Ratio & IRR 95\%-CI \\
\hline Omitting Goldman 2011 & & $0.75[0.39 ; 1.43]$ \\
\hline Omitting Petrovic 2015 & & $0.67[0.33 ; 1.35]$ \\
\hline Omitting RSVP & & $0.76[0.41 ; 1.40]$ \\
\hline Omitting Yoo 2012 & & $0.79[0.44 ; 1.43]$ \\
\hline Omitting Stand-in-Y & & $0.76[0.38 ; 1.53]$ \\
\hline Omitting RAPCO & & $0.80[0.44 ; 1.47]$ \\
\hline Random effects model & 1 & $0.76[0.42 ; 1.36]$ \\
\hline & 0.5 & \\
\hline
\end{tabular}

FIGURE E6. Leave-one-out analysis of (A) long-term repeated revascularization and (B) long-term myocardial infarction. IRR, Incidence rate ratio; $C I$, confidence interval; $R A$, radial artery; $S V G$, saphenous vein graft.

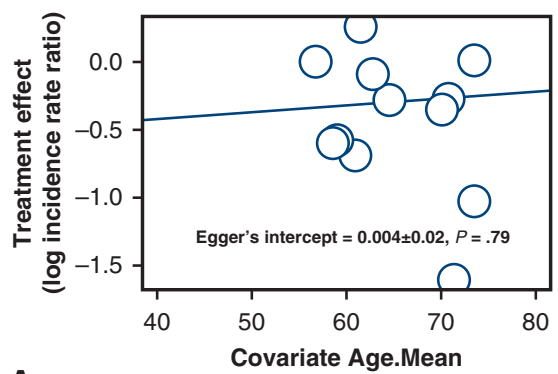

A

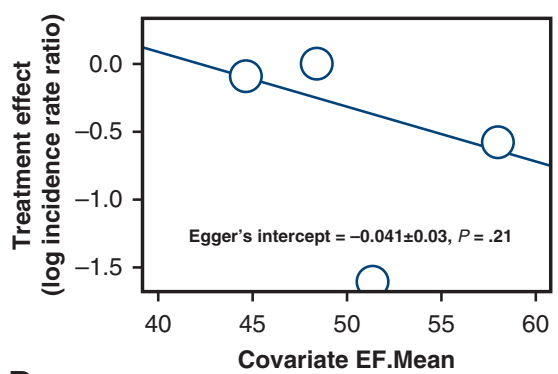

D

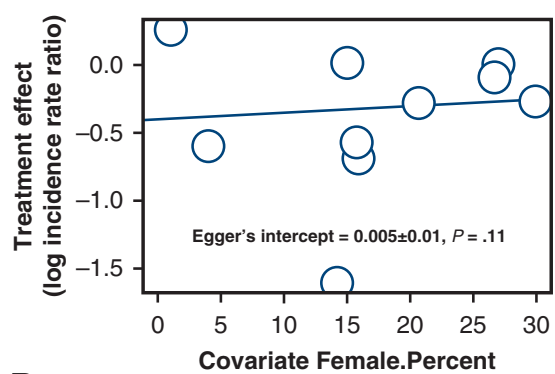

B

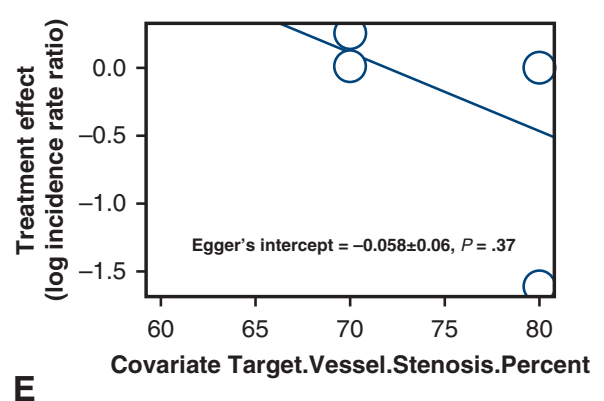

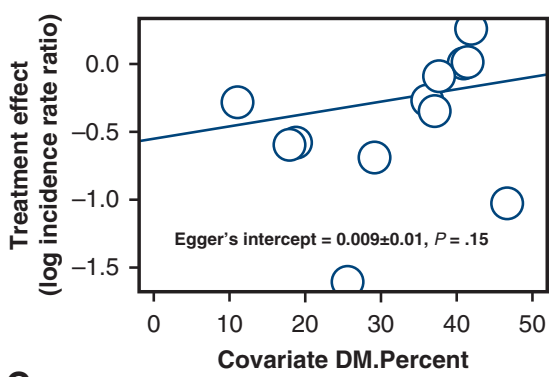

C

FIGURE E7. Meta-regression for the primary outcome (long-term mortality): (A) mean age; (B) Female sex percentage; (C) DM percentage; (D) mean EF; and (E) target vessel stenosis percentage. $D M$, Diabetes mellitus; $E F$, ejection fraction. 
TABLE E1. Long term mortality: Summary of the statistics calculation

\begin{tabular}{|c|c|c|c|c|c|c|c|c|c|c|c|c|c|}
\hline $\begin{array}{l}\text { First author/ } \\
\text { acronym }\end{array}$ & Type & $\begin{array}{c}\text { Follow- } \\
\text { up, y }\end{array}$ & $\begin{array}{l}\text { RA } \\
\text { total }\end{array}$ & $\begin{array}{l}\text { SVG } \\
\text { total }\end{array}$ & $\begin{array}{c}\text { RA } \\
\text { events }\end{array}$ & $\begin{array}{c}\text { KM } \\
\text { nonevent } \\
\text { rate } \mathbf{R A}\end{array}$ & $\begin{array}{c}\text { SVG } \\
\text { events }\end{array}$ & $\begin{array}{c}\text { KM } \\
\text { nonevent } \\
\text { rate SVG }\end{array}$ & $\begin{array}{c}\text { Log } \\
\text { rank } \\
P \text { value }\end{array}$ & IRR & LN(IRR) & $\begin{array}{c}\text { SE [LN } \\
(\text { IRR)] }\end{array}$ & $\begin{array}{c}\text { IRR } \\
\text { calculation } \\
\text { method }\end{array}$ \\
\hline $\begin{array}{l}\text { Benedetto and } \\
\text { Codispoti, } 2013^{15}\end{array}$ & Non-RCT & $6.4^{*}$ & 809 & 809 & & & & & & 0.75 & -0.29 & 0.14 & HR \\
\hline Cohen et al, $2001^{16}$ & Non-RCT & $3 \dagger$ & 478 & 956 & 19 & 0.96 & 76 & 0.92 & 0.64 & 0.50 & -0.69 & 0.26 & KM \\
\hline $\begin{array}{l}\text { Goldman } \\
\text { et al, } 2011^{24}\end{array}$ & RCT & $1 \dagger$ & 366 & 367 & 9 & & 7 & & & 1.29 & 0.25 & 0.49 & Events (RR) \\
\hline Lin et al, $2013^{17}$ & Non-RCT & $9.4^{*}$ & 260 & 260 & & & & & & 0.76 & -0.27 & 0.12 & HR \\
\hline $\begin{array}{l}\text { Locker } \\
\qquad \text { et al, } 2013^{18}\end{array}$ & Non-RCT & $7.6^{*}$ & 168 & 7281 & & & & & & 0.56 & -0.58 & 0.20 & HR \\
\hline $\begin{array}{l}\text { Petrovic } \\
\qquad \text { et al, } 2015^{19}\end{array}$ & RCT & $8 \dagger$ & 100 & 100 & 12 & & 12 & & & 1.00 & 0.00 & 0.41 & Events (RR) \\
\hline $\begin{array}{l}\text { Santarpino } \\
\text { et al, } 2010^{20}\end{array}$ & Non-RCT & $3.17 *$ & 150 & 180 & & 0.95 & & 0.75 & 0.046 & 0.20 & -1.61 & 0.81 & KM \\
\hline $\begin{array}{l}\text { Schwann } \\
\text { et al, } 2015^{21}\end{array}$ & Non-RCT & $15 \dagger$ & 2966 & 2966 & & & & & & 0.91 & -0.09 & 0.11 & HR \\
\hline $\begin{array}{l}\text { RAPCO (Hayward } \\
\text { et al, 2008) }\end{array}$ & RCT & $6.2^{*}$ & 113 & 112 & & & & & & 1.01 & 0.01 & 0.35 & HR (inverted) \\
\hline $\begin{array}{l}\text { Stand-in-Y } \\
\text { (Nasso et al, } \\
2009)^{23}\end{array}$ & $\mathrm{RCT}$ & $2.01 *$ & 201 & 202 & 7 & & 10 & & & 0.70 & -0.35 & 0.49 & Events (RR) \\
\hline Yoo et al, $2012^{13}$ & RCT & $0.67 *$ & 35 & 25 & & & & & & 0.265 & -1.328 & 0.874 & HR from IPD \\
\hline $\begin{array}{l}\text { RSVP (Collins } \\
\text { et al, 2008) }\end{array}$ & RCT & $5^{*}$ & 82 & 60 & & & & & & 0.544 & -0.609 & 0.763 & HR from IPD \\
\hline $\begin{array}{l}\text { IRR: If survival curve n } \\
\text { group-specific patient-ye } \\
\text { SE[LN(IRR)]: If HR and } \\
\text { was available, then it wa } \\
\text { was calculated as } \mathrm{SE}[\mathrm{LN} \\
S V G \text {, saphenous vein gra } \\
H R \text {, hazard ratio; } R R \text {, rel }\end{array}$ & $\begin{array}{l}5 \text { of follow-u } \\
5 \% \text { confide } \\
\text { calculated as } \\
2 \mathrm{R})]=\mathrm{SQR} \\
K M, \mathrm{Kaplan} \\
\text { ive risk; } I P D\end{array}$ & $\begin{array}{l}\text { op are avail } \\
\text { nce interva } \\
\text { LN(IRR)/I } \\
\text { T (1/RA eve } \\
\text {-Meier; IR } \\
\text {, individual }\end{array}$ & lable, the & $\begin{array}{l}\text { en IRR }= \\
\text { reported } \\
\text { SINV }(P\end{array}$ & $\begin{array}{l}=[\mathrm{RA} \text { eve } \\
\mathrm{l} \text {, then it } \mathrm{v}\end{array}$ & was calcul & as Ll & Upper $95 \%$ C & CI) $-\mathrm{LN}$ & $\begin{array}{l}\text { Excel. } \\
\text { oft Ex }\end{array}$ & $\begin{array}{l}\mathrm{CI}) / 3.92 \\
\text { only actual } \\
(\text { see Yanag }\end{array}$ & $\begin{array}{l}\text { of patient } \\
\text { patient-ye } \\
\text { f the survi } \\
\text { vents were } \\
\text { va et } \mathrm{al}^{10} \text { ). }\end{array}$ & $\begin{array}{l}\text { s with events and } \\
\text { ears of follow-up]. } \\
\text { ival curve } P \text { value } \\
\text { available, then it } \\
R A \text {, Radial artery; } \\
\text { nized clinical trial; }\end{array}$ \\
\hline
\end{tabular}

TABLE E2. Demographics of the included observational studies (unmatched groups)

\begin{tabular}{|c|c|c|c|c|c|c|}
\hline Study & Arm & Age, $y$, mean SD & Female, n (\%) & DM, n (\%) & EF, mean SD & COPD, n (\%) \\
\hline \multirow[t]{2}{*}{ Benedetto and Codispoti, $2013^{15}$} & RA & $65.0 \pm 10.0$ & $191(20.4)$ & $95(10.1)$ & $\mathrm{NR}^{*}$ & $110(11.8)$ \\
\hline & SVG & $68.0 \pm 9.0$ & $1452(18.0)$ & $928(11.5)$ & $\mathrm{NR}^{*}$ & $880(10.9)$ \\
\hline \multirow[t]{2}{*}{ Cohen et al, $2001^{16}$} & RA & NR & NR & NR & NR & NR \\
\hline & SVG & NR & NR & NR & NR & NR \\
\hline \multirow[t]{2}{*}{ Lin et al, $2013^{17}$} & RA & NR & NR & NR & NR & NR \\
\hline & SVG & NR & NR & NR & NR & NR \\
\hline \multirow[t]{2}{*}{ Locker et al, $2013^{18}$} & RA & NR & NR & NR & NR & NR \\
\hline & SVG & $68.0 \pm 9.0$ & $(24.8)$ & $(33.5)$ & $55.0 \pm 14.0$ & $(11.7)$ \\
\hline \multirow[t]{2}{*}{ Santarpino et al, $2010^{20}$} & RA & $72.2 \pm 9.9$ & $20(13.3)$ & 49 (32.6) & $53.5 \pm 9.9$ & $24(13.3)$ \\
\hline & SVG & $70.5 \pm 9.6$ & $26(14.4)$ & $36(20.0)$ & $49.2 \pm 10.7$ & $27(18.0)$ \\
\hline \multirow[t]{2}{*}{ Schwann et al, $2015^{21}$} & RA & $60.2 \pm 9.7$ & $1026(34.4)$ & $1694(37.2)$ & $49 \pm 11$ & $779(17.1)$ \\
\hline & SVG & $67.3 \pm 9.9$ & $2305(34.4)$ & $2541(37.9)$ & $48 \pm 12$ & $1748(26.1)$ \\
\hline \multirow[t]{2}{*}{ Tranbaugh et al, $2010^{27}$} & RA & $57.1 \pm 8.5$ & $270(17.3)$ & $551(35.3)$ & $48.2 \pm 11.4$ & $282(18.1)$ \\
\hline & SVG & $68.4 \pm 9.3$ & $933(34.4)$ & $1038(38.3)$ & $46.1 \pm 13.2$ & $881(32.5)$ \\
\hline
\end{tabular}

$S D$, Standard deviation; $D M$, diabetes mellitus; $E F$, ejection fraction; $C O P D$, chronic obstructive pulmonary disease; $R A$, radial artery; $N R$, not reported; $S V G$, saphenous vein graft. *EF reported as categories. 
TABLE E3. Cochrane collaboration's tool for the included randomized trials

\begin{tabular}{|c|c|c|}
\hline Risk of bias & Authors' judgment & Support for judgment \\
\hline \multicolumn{3}{|l|}{ Goldman et al, $2011^{24}$} \\
\hline Random sequence generation & Low risk & $\begin{array}{l}\text { Patients were assigned in a 1:1 ratio to RA or SVG using permuted blocks } \\
\text { randomization. }\end{array}$ \\
\hline Allocation concealment & Unclear & No info. \\
\hline Blinding of participants and personnel & NA & Blinding not applicable. \\
\hline Blinding of outcome assessment & Low risk & $\begin{array}{l}\text { The central angiography readers were blinded as to which patients had radial } \\
\text { artery grafts vs saphenous vein grafts. }\end{array}$ \\
\hline Incomplete outcome data & Low risk & Five hundred thirty-three patients $(73 \%)$ had 1-y angiograms. \\
\hline Selective reporting & Low risk & All expected outcomes reported. \\
\hline Other bias & Low risk & No other sources of bias to report. \\
\hline \multicolumn{3}{|l|}{ Petrovic et al, $2015^{19}$} \\
\hline Random sequence generation & Unclear & $\begin{array}{l}\text { Patients were randomized in 1:1 fashion to receive either LITA and RA grafts or } \\
\text { LITA and SVGs. }\end{array}$ \\
\hline Allocation concealment & Unclear & No info. \\
\hline Blinding of participants and personnel & NA & Blinding not applicable. \\
\hline Blinding of outcome assessment & Unclear & No info. \\
\hline Incomplete outcome data & Low risk & All patients were followed for 8 y or until death. \\
\hline Selective reporting & Low risk & All expected outcomes reported. \\
\hline Other bias & Low risk & No other sources of bias to report. \\
\hline \multicolumn{3}{|l|}{ Stand-in-Y (Nasso et al, 2009) $)^{23}$} \\
\hline Random sequence generation & Low risk & Patients randomized with the aid of a computerized algorithm \\
\hline Allocation concealment & Unclear & No info \\
\hline Blinding of participants and personnel & NA & Blinding not applicable \\
\hline Blinding of outcome assessment & Unclear & No info \\
\hline Incomplete outcome data & Low risk & Three patients were lost at follow-up. \\
\hline Selective reporting & Low risk & All expected outcomes reported \\
\hline Other bias & Low risk & No other sources of bias to report \\
\hline \multicolumn{3}{|l|}{ Yoo et al, $2012^{13}$} \\
\hline Random sequence generation & Unclear & Sixty patients were allocated in a random ratio of $1: 1$ to 2 groups. \\
\hline Allocation concealment & Unclear & No info. \\
\hline Blinding of participants and personnel & NA & Blinding not applicable. \\
\hline Blinding of outcome assessment & Unclear & No info. \\
\hline Incomplete outcome data & Unclear & No info. \\
\hline Selective reporting & Low risk & All expected outcomes reported. \\
\hline Other bias & Low risk & No other sources of bias to report \\
\hline \multicolumn{3}{|l|}{ RSVP (Collins et al, 2008) ${ }^{14}$} \\
\hline Random sequence generation & Low risk & $\begin{array}{l}\text { Randomization codes were obtained by use of a random number generator } \\
\text { sequence. }\end{array}$ \\
\hline Allocation concealment & Low risk & Sealed in brown envelopes that were sequentially numbered. \\
\hline Blinding of participants and personnel & NA & Blinding not applicable. \\
\hline Blinding of outcome assessment & Unclear & No info. \\
\hline Incomplete outcome data & Low risk & $\begin{array}{l}\text { Follow-up angiography was performed in } 103 \text { of the } 134 \text { patients alive and not } \\
\text { withdrawn from the study }(77 \%) \text {. }\end{array}$ \\
\hline Selective reporting & Low risk & All expected outcomes reported. \\
\hline Other bias & Low risk & No other sources of bias to report. \\
\hline \multicolumn{3}{|l|}{ Muneretto et al, $2004^{28}$} \\
\hline Random sequence generation & Unclear & The patients were randomly assigned to group 1 or group 2 . \\
\hline Allocation concealment & Unclear & No info. \\
\hline Blinding of participants and personnel & NA & Blinding not applicable. \\
\hline Blinding of outcome assessment & Unclear & No info. \\
\hline \multirow[t]{2}{*}{ Incomplete outcome data } & Low risk & $\begin{array}{l}\text { We evaluated } 76 \text { patients ( } 98 \%) \text { in group } 1 \text { and } 76 \text { patients }(100 \%) \text { in group } 2 \\
\text { by means of clinical visits and cycloergometric tests. }\end{array}$ \\
\hline & & $\begin{array}{l}\text { Angiographic evaluation was performed in } 89.6 \% \text { and } 88.1 \% \text { of hospital } \\
\text { survivors in groups } 1 \text { and } 2 \text {, respectively. }\end{array}$ \\
\hline
\end{tabular}


TABLE E3. Continued

\begin{tabular}{|c|c|c|}
\hline Risk of bias & Authors' judgment & Support for judgment \\
\hline Selective reporting & Low risk & All expected outcomes reported. \\
\hline Other bias & Low risk & No other sources of bias to report. \\
\hline \multicolumn{3}{|l|}{ RAPCO (Hayward et al, 2008) ${ }^{22}$} \\
\hline Random sequence generation & Low risk & $\begin{array}{l}\text { The choice of the second conduit was determined by random assignment. } \\
\text { Random numbers were generated from the Minitab statistical package } \\
\text { (Minitab, Inc, State College, } \mathrm{Pa} \text { ) }\end{array}$ \\
\hline Allocation concealment & Low risk & Numbers were placed in sealed envelopes. \\
\hline Blinding of participants and personnel & NA & Blinding not applicable. \\
\hline Blinding of outcome assessment & Unclear & No info. \\
\hline Incomplete outcome data & Low risk & Survival was confirmed with the National Death Index, a register of all deaths. \\
\hline Selective reporting & Low risk & All expected outcomes reported. \\
\hline Other bias & Low risk & No other sources of bias to report. \\
\hline
\end{tabular}

$R A$, Radial artery; $S V G$, saphenous vein graft; N/A, not available; $L I T A$, left internal thoracic artery.

TABLE E4. Estimate survival at 1 and 5 years and at the end of follow-up from reconstructed Kaplan-Meier curves

\begin{tabular}{lccc}
\hline Graft & HR 1 y & HR 5 y & HR end of follow-up \\
\hline RA & $97.2 \%(96.8 \%-97.6 \%)$ & $91.9(91.2 \%-92.7 \%)$ & $69.0 \%(67.1 \%-71.0 \%)$ at $169.6 \mathrm{mo}$ \\
SVG & $95.1 \%(94.7 \%-95.6 \%)$ & $83.4 \%(82.6 \%-84.2 \%)$ & $50.1 \%(48.7 \%-51.6 \%)$ at $167.99 \mathrm{mo}$ \\
\hline
\end{tabular}

Ranges in parentheses are $95 \%$ confidence intervals. $H R$, Hazard ratio; $R A$, radial artery; $S V G$, saphenous vein graft. 
TABLE E5. Results of meta-regression for the primary outcome

\begin{tabular}{lll}
\hline Variable source & \multicolumn{1}{c}{ Variables } & Meta-regression results \\
\hline Matched & Mean age & Beta $=0.0049, P=.7850$ \\
Matched & Female \% (mean) & Beta $=-0.0048, P=.6480$ \\
Matched & Diabetes \% (mean) & Beta $=0.0092, P=.1511$ \\
Matched & Mean EF\% & Beta $=-0.0405, P=.2135$ \\
Matched & RA \% target vessel stenosis & Beta $=-0.0578, P=.3658$ \\
Unmatched & Mean age & Beta $=0.0049, P=.7850$ \\
Unmatched & Mean age absolute difference & Beta $=-0.0490, P=.3379$ \\
Unmatched & Female \% (mean) & Beta $=0.0132, P=.4267$ \\
Unmatched & Female \% absolute difference & Beta $=-0.0058, P=.8773$ \\
Unmatched & Diabetes $\%$ (mean) & Beta $=0.0136, P=.2667$ \\
Unmatched & Diabetes \% absolute difference & Beta $=-0.0267, P=.0252$ \\
Unmatched & Mean EF\% & Beta $=-0.5344, P=.0602$ \\
Unmatched & Mean EF\% absolute difference & Beta $=-0.4593, P=.0598$ \\
\hline
\end{tabular}

EF, Ejection fraction; $R A$, radial artery.

TABLE E6. Results of meta-regression for operative mortality

\begin{tabular}{lll}
\hline Variable source & \multicolumn{1}{c}{ Variables } & \multicolumn{1}{c}{ Meta-regression results } \\
\hline Matched & Mean age & Beta $=0.0030, P=.9364$ \\
Matched & Female \% (mean) & Beta $=-0.0052, P=.7578$ \\
Matched & Diabetes \% (mean) & Beta $=0.0001, P=.9922$ \\
Matched & Mean EF\% & Beta $=-0.1648, P=.3762$ \\
Matched & $\begin{array}{c}\text { RA \% target } \\
\text { vessel stenosis }\end{array}$ & Beta $=-0.0806, P=.4317$ \\
\hline
\end{tabular}

$E F$, Ejection fraction; $R A$, radial artery. 